\title{
GnRH or Estradiol Benzoate combination with CIDR improves in-vivo embryo production in bovines (Bos indicus and Bos taurus) under subtropics
}

\author{
Khalid Mahmood ${ }^{1}$, Muhammad Zahid Tahir ${ }^{1}$, Mahboob Butt ${ }^{2}$, Shazia Mansoor Qureshi ${ }^{3}$, Amjad Riaz ${ }^{\text {Corresp. } 1}$ \\ 1 Department of Theriogenology, University of Veterinary and Animals Sciences, Lahore, Punjab, Pakistan \\ 2 Department of Livestock Management, University of Veterinary and Animal Sciences, Lahore, Punjab, Pakistan \\ ${ }^{3}$ Center of Excellence for Bovine Genetics, Okara, Punjab, Pakistan \\ Corresponding Author: Amjad Riaz \\ Email address: dramjadriaz@uvas.edu.pk
}

Multiple Ovulation and Embryo Transfer (MOET) technology is a potential technique to upgrade livestock species' genetics. The varied response to super-stimulatory treatments remains one of the limiting factors to this technology's widespread use. The present study was aimed to improve the superovulation response and in-vivo embryo production by using Control internal drug release (CIDR)-GnRH or CIDR-EB (Estradiol Benzoate) along with conventional superovulation protocol in Holstein Frisian (HF):Bos taurus; $\mathrm{n}=42$ ) and Crossbred (XB: Cholistani (Bos indicus) x HF; $\mathrm{n}=28$ ) cows. In the CIDR-GnRH / CIDR-EB treatment, CIDR was implanted in the cows after confirming the presence of a corpus luteum (CL) on the $8^{\text {th }}$ day after estrus. $2 \mathrm{ml} \mathrm{GnRH} \mathrm{(Lecirelin} \mathrm{acetate} 0.0262 \mathrm{mg} / \mathrm{ml}$ ) or $2 \mathrm{mg}$ EB was also administered in CIDR-GnRH / CIDR-EB groups, respectively. Both groups were given super-stimulatory treatment from the $11^{\text {th }}$ day after estrus (FSH in tapering doses twice a day for four consecutive days). On day 13 , two doses of $2 \mathrm{ml}$ prostaglandin (75 $\mu \mathrm{g} / \mathrm{ml}$ of dextrorotatory cloprostenol) were administered (am: pm), and CIDR was removed the following day. Two artificial inseminations (Al) of the cows were performed (12 hours apart) on the $15^{\text {th }}$ day. No CIDR and GnRH/E.B were given in the control group, but the remaining superovulation protocol was the same. Later on, seven days after the first Al, non-surgical embryo flushing was done. The transferable embryos produced from three different superovulation protocols were then transferred into the recipient cows $(n=90)$ for determining their fertility. Statistical analysis revealed that the number of super-estrus follicles (SEF), multiple corpora lutea (MCL), ovulation/fertilization percentage, fertilized structures recovered (FSR), and transferable embryos (TEs) remained significantly higher $(p<0.05)$, and days taken for return to estrus (RTE) after embryo collection remained significantly lower $(p<0.05)$ in CIDR-GnRH $(n=18)$ and CIDR-EB $(n=15)$ groups as 
compared to the control $(n=37)$. The comparison between $X B$ and HF cows revealed that the TEs production in $\mathrm{CIDR}-\mathrm{GnRH}(\mathrm{XB}=5$ vs $\mathrm{HF}=13)$ and $\mathrm{CIDR}-\mathrm{EB}(\mathrm{XB}=6$ vs $\mathrm{HF}=9)$ based superovulation protocols were $11.60+4.08$ vs $04.31+0.98$ and $09.33+1.78$ vs $05.22+$ 1.36 , respectively. TEs production in XB cows $(n=5)$ of the CIDR-GnRH group was significantly higher $(11.60+4.08)$ than other groups. On the other hand, the days taken for RTE after embryo collection remained significantly lower $(p<0.05)$ in HF cows of treatment groups. However, the fertility of TEs was neither affected significantly $(p>0.05)$ by the superovulation protocol used nor by breed differences among donor cows. In conclusion, using CIDR-GnRH or CIDR-EB along with conventional superovulation protocol may enhance the efficiency of MOET programs in cattle. Furthermore, XB donor cows demonstrated a better performance than HF donor cows under subtropical conditions. 
1 GnRH or Estradiol Benzoate combination with CIDR improves in-vivo embryo production

2 in bovines (Bos Indicus and Bos Taurus) under subtropics

3

4 Khalid Mahmood ${ }^{1}$, Muhammad Zahid Tahir ${ }^{1}$, Mahboob Ahmad Butt ${ }^{2}$, Shazia Mansoor Qureshi ${ }^{3}$, 5 Amjad Riaz ${ }^{1 *}$

6

$7{ }^{1}$ Department of Theriogenology, University of Veterinary and Animals Sciences, Lahore,

8 Pakistan

92 Department of Livestock Management, University of Veterinary and Animals Sciences, Lahore, 10 Pakistan

$11{ }^{3}$ Center of Excellence for Bovine Genetics, Okara, Punjab, Pakistan.

12

\section{CIDR Based Superovulation in Bovines}

15

*Correspondence:

Amjad Riaz

25

Email: dramjadriaz@uvas.edu.pk

27

Phone: +92333-5262325

28

\section{ABSTRACT:}


31

32

33

34

35

36

37

38

39

40

41

42

43

44

45

46

47

48

49

50

51

52

Multiple Ovulation and Embryo Transfer (MOET) technology is a potential technique to upgrade livestock species' genetics. The varied response to super-stimulatory treatments remains one of the limiting factors to this technology's widespread use. The present study was aimed to improve the superovulation response and in-vivo embryo production by using Control internal drug release (CIDR)-GnRH or CIDR-EB (Estradiol Benzoate) along with conventional superovulation protocol in Holstein Frisian (HF): Bos taurus; n=42) and Crossbred (XB: Cholistani (Bos indicus) x HF; $\mathrm{n}=28$ ) cows. In the CIDR-GnRH / CIDR-EB treatment, CIDR was implanted in the cows after confirming the presence of a corpus luteum (CL) on the $8^{\text {th }}$ day after estrus. $2 \mathrm{ml} \mathrm{GnRH} \mathrm{(Lecirelin} \mathrm{acetate} 0.0262 \mathrm{mg} / \mathrm{ml}$ ) or $2 \mathrm{mg}$ EB was also administered in CIDR-GnRH / CIDR-EB groups, respectively. Both groups were given super-stimulatory treatment from the $11^{\text {th }}$ day after estrus (FSH in tapering doses twice a day for four consecutive days). On day 13 , two doses of $2 \mathrm{ml}$ prostaglandin $(75 \mu \mathrm{g} / \mathrm{ml}$ of dextrorotatory cloprostenol) were administered (am: pm), and CIDR was removed the following day. Two artificial inseminations (AI) of the cows were performed (12 hours apart) on the $15^{\text {th }}$ day. No CIDR and GnRH/E.B were given in the control group, but the remaining superovulation protocol was the same. Later on, seven days after the first AI, non-surgical embryo flushing was done. The transferable embryos produced from three different superovulation protocols were then transferred into the recipient cows $(n=90)$ for determining their fertility. Statistical analysis revealed that the number of superestrus follicles (SEF), multiple corpora lutea (MCL), ovulation/fertilization percentage, fertilized structures recovered (FSR), and transferable embryos (TEs) remained significantly higher $(p<0.05)$, and days taken for return to estrus (RTE) after embryo collection remained significantly lower $(p<0.05)$ in CIDR-GnRH $(n=18)$ and CIDR-EB $(n=15)$ groups as compared to the control $(n=37)$. The comparison between XB and HF cows revealed that the TEs production in CIDR-GnRH (XB=5 vs $\mathrm{HF}=13)$ and $\mathrm{CIDR}-\mathrm{EB}(\mathrm{XB}=6 \mathrm{vs} \mathrm{HF}=9)$ based superovulation protocols were $11.60 \pm 4.08$ vs $04.31 \pm 0.98$ and $09.33 \pm 1.78$ vs $05.22 \pm 1.36$, respectively. TEs production in XB cows $(n=5)$ of the CIDR-GnRH group was significantly higher $(11.60 \pm 4.08)$ than other groups. On the other hand, the days taken for RTE after embryo collection remained significantly lower $(p<0.05)$ in HF cows of treatment groups. However, the fertility of TEs was neither affected significantly $(p>0.05)$ by the superovulation protocol used nor by breed differences among donor cows. In conclusion, using CIDR-GnRH or CIDR-EB along with conventional superovulation protocol may enhance the efficiency of MOET programs 
62 in cattle. Furthermore, XB donor cows demonstrated a better performance than HF donor cows

63 under subtropical conditions.

64 Keywords: ETT in Pakistan; Synchronization of the follicular wave; Embryos; Bovine

65

66

\section{INTRODUCTION:}

In the developing countries, over time increase in population has significantly increased the demand for animal source products such as meat and milk (Mekonnen \& Hoekstra 2012). The key to successfully meet the increasing demand for livestock products is to enhance productivity through improved genetic gain (Lawanson \& Oduntan 2020). The desire to improve animal genetics can be achieved using reproductive biotechnologies such as AI and MOET (Wheeler et al. 2010; Naranjo-Chacón et al. 2019). Generally, crossbreeding is considered an effective tool for quick genetic improvement of low milk-producing cows (Galukande et al., 2013). However, commercial dairy production in developing countries cannot sustain economically with F1 cows from nondescript animals due to low milk production potential. Raising a purebred stock of dairy cows to produce F1 cows is confronted with constraints, such as the unavailability of the required number of native cattle and national breeding policies (Leroy et al., 2016). However, the propagation of high milk-producing readily available XB and HF cows through the MOET program to produce replacement heifers is a practical model (Baruselli et al. 2018; Jarvis 2019; Madalena 2008).

For developing countries like Pakistan, where most of the population is, directly and indirectly, dependent on agriculture, it becomes imperative to evaluate and disseminate reproductive biotechnologies-based methods to enhance animal productivity. Warriach et al. 2015 revealed the significance and the widespread dissemination of artificial insemination techniques in Pakistan. However, this study pointed out that the embryo transfer technique has yet to significantly succeed in Pakistan. Mebratu et al., 2020 highlighted that the non-availability of the technical staff, the high cost involved in IVF / MOET, and the lack of fixed timeline-based superovulation protocols in subtropical conditions are the underlying factors for ET's low adaptability in developing countries.

In recent times, considerable advancement has been made in controlling ovarian function and biochemistry of gonadotropins; however, the inherent factors affecting superovulation outcomes in donor animals are still partially understood (Bó \& Mapletoft 2014; Mapletoft 2018; Phillips \& 
Jahnke 2016; Viana et al. 2018). The preferred hormone for super-stimulation is FSH (folliclestimulating hormone), as animals treated with eCG (equine chorion gonadotropin) show abnormal LH profile and declined ovulation and fertilization rates (Murphy 2018).

Traditionally, ovaries are super-stimulated during mid-cycle, i.e., 8-12 days after estrus, because in cows with two follicular waves, an emergence of the $2^{\text {nd }}$ follicular wave and the cohort of growing follicles is expected during mid-cycle (Abdel-Khalek 2010). However, this phenomenon differs in individual cows with three follicular waves (Mapletoft et al. 2002; Adams \& Singh 2021; Hassan et al. 2021). The $2^{\text {nd }}$ follicular wave emerges one to two days earlier in cows with three follicular waves. Meanwhile, treatment with gonadotrophin on the day of follicle wave emergence results in a better super-stimulatory response (Mapletoft \& Bó 2018).

The ability to selectively induce the emergence of follicular waves allows superstimulation to be initiated regardless of the estrous cycle stage and without the need to detect estrus and wait for the mid-cycle to start hormonal therapy (Bo et al. 2002; Bó \& Mapletoft 2014; Jahnke \& Youngs 2021). Previously, progesterone, estradiol, or GnRH has been used for elective emergence of follicular waves with remarkable success (Bó et al. 2009; Guerrero et al. 2009; Nasser et al. 2011; Rivera et al. 2011). Furthermore, the initiation of superovulation at the time of follicular wave emergence improves embryo production in cattle (Bó \& Mapletoft 2014; Mikkola et al. 2020). A recent study from Mexico has reported improved embryo production from XB dairy cows through a modified superovulation protocol in tropical conditions (Chacón et al. 2020 ). However, no specific superovulation protocol with promising results for exotic (Bos Taurus) and XB (Bos taurus x Bos indicus) cows under subtropical conditions has been reported from Pakistan. Therefore, the present study is an attempt to bridge this research gap by evaluating the superovulation response in the Pakistani-raised cows. The research was carried out to determine the optimal superovulation response and in-vivo embryo production in bovines by using CIDR-GnRH or CIDR-EB for synchronizing follicular wave before the initiation of superovulation in Holstein Frisian (HF: Bos taurus; n=42) and Crossbred (XB: Cholistani (Bos indicus) x HF; $\mathrm{n}=28$ ) cows under subtropical environment prevalent in Pakistan.

\section{MATERIALS AND METHODS}

\subsection{Animal Selection and Ethical Issues}

A total of 70 donor cows $(\mathrm{HF}=42$ and $\mathrm{XB}=28)$ with proper vaccination history and high milk production were super-stimulated in this study. All of the selected cows were of relative 
124 parity (1-3), age (3-8 years), and BCS more than 2.5 (Roche et al. 2009). The corresponding

125 Committee for Animal Care, CEBG-Okara (QPY-5.3-01), approved all procedures involving

126 animals' welfare and ethics. The Guiding Principles for the Care and Use of Laboratory Animals

127 (Baumans 2005; Naderi et al. 2012) were strictly adhered to in this research work.

128

129

\subsection{Management Practices}

130 The study was conducted at the Centre of Excellence for Bovine Genetics (CEBG), Okara, 131 Punjab, Pakistan, located at N 30 48' 29", E 73 26' 45". To avoid heat stress, experiments were

132

133

134

135

136

137

138

139

140

141

142

143

144

145

146

147

148

149

150

151

152

153 carried out during moderate to colder months (October to March) with an average daily temperature of $22^{\circ} \mathrm{C}$. The annual average rainfall in the study area was $509 \mathrm{~mm}$, and the average daily temperature ranged between $3^{\circ} \mathrm{C}$ (in December) to $47^{\circ} \mathrm{C}$ (in June/July). All sampled cows were housed in the open sheds, and their deworming was performed 30 days prior to the commencement of this study. All sampled cows were offered fresh green fodder/maize silage and concentrate with free access to fresh drinking water. Any animal showing abnormal vaginal discharge at the time of heat or history of recent illness was not selected for this study.

\subsection{Superovulation of donor animals}

Cows in the natural estrus were subjected to three superovulation treatments, i.e., CIDR-GnRH based, CIDR-EB based, and conventional superovulation. Donor cows of relative parity and age were randomly selected for these treatments. In the CIDR-GnRH group $(n=18)$ animals, the presence of CL was confirmed on Day 8 of the estrus cycle through ultrasonography (Bényei et al. 2006; Kayacik et al. 2006), and 2ml GnRH (Dalmarelin; FATRO, Italy) was administered along with intravaginal placement of $1.38 \mathrm{~g}$ of progesterone CIDR (Controlled Internal Drug Release; Pfizer, USA). From Day 11-14, 400mg of FSH (Folltropin-V; Bioniche Animal Health; Canada) was administered in 8 tapering (70mg, 60mg, 40mg, and 30mg) doses (AM: PM). On Day 13, 2ml prostaglandin (Dalmazin; FATRO-Italy) was administered twice (AM: PM), followed by removal of CIDR on Day 14. On day 15, administration of $2 \mathrm{ml} \mathrm{GnRH}$ and AI was performed. The cows in super-estrus were inseminated twice (12 hours apart) after confirmation of heat signs (Roelofs et al. 2010) with commercially available semen of HF bulls of proven fertility. The embryos were collected through non-surgical flushing on Day 22 (7 days post-AI), and all the animals received $2 \mathrm{ml}$ of prostaglandin on Day 25 to induce luteolysis (Fig. 1a). 
154 In the CIDR-EB group $(\mathrm{n}=15)$, the animals were injected with $2 \mathrm{mg}$ Estradiol Benzoate USP

155 (Sigma Aldrich, USA) instead of GnRH. The remaining timeline was the same as described in 156 the CIDR-GnRH group (Fig. 1b).

157 In the conventional (control) superovulation group $(n=37)$, the animals were not treated with

$158 \mathrm{CIDR}$ and GnRH / EB, but the remaining superovulation timeline was the same as described in 159 treatment groups (Fig 1c). All of the procedures were performed by a qualified team of two 160 veterinarians and three technicians.

161

162

163

164

165

166

167

168

169

170

171

172

173

174

175

176

177

178

179

180

181

182

183

\subsection{Ultrasound scanning}

Each animal's ovaries were scanned using a 7.5 MHz linear rectal probe (iMAGO-S ECM, France) to check the existence of ovulatory follicle and CL on "Day 0" and "Day 8" of the estrous cycle, respectively. The scanning was continued on day 10, 11, and 12 to determine the pattern of follicular wave development and to rule out the presence of the dominant follicle. Any animal having a persistent dominant follicle till day 11 was not given FSH treatment. The ovarian scanning of donor animals was also performed on the day of super-estrus (before AI) and on the day of embryo collection. This was to determine the superovulation response and to count the total number of CLs present on the superovulated ovaries.

\subsection{Embryo flushing and grading}

Embryos were collected from the donor animals using 18-24 gauge two-way Foley end Silicone catheter and flushing tubing after epidural anesthesia. Each horn was flushed using $480 \mathrm{ml}$ of flushing media (Boviflush; Mintub, Germany), and the flushing fluid was filtered via $75 \mu$ mesh (Miniflush, Mintub, Germany). The mucus attached to the membranous part of the embryo filter was washed into a $64 \mathrm{~mm}$ petri dish using two-piece syringes and flushing media. Embryos were searched under $12 \mathrm{X}$ or $25 \mathrm{X}$ magnification of stereo zoom microscope and transferred into the holding media (Bovihold, Mintub, Germany). Embryos were washed (with holding media) up to eight times to remove any debris before evaluating their quality under $50 \mathrm{X}$ magnification based on the regularity of shape, cellular mass, compactness of blastomere, the shape of zona pellucida (ZP), and the presence of extruded cells. The classification of the embryo was done based on its stage of development. Embryos having more than $85 \%$, 50-85\%, less than 50\% compact cellular 
184 mass were classified as A, B, and C grade embryos, respectively (Stringfellow \& Givens 2017).

185 Only A and B-grade embryos were considered for calculating TEs per donor per collection.

186

187

\subsection{Fertility Trial of Embryos}

188

189

190

191

192

193

194

195

196

197

198

199

200

201

202

203

204

205

206

207

208

209

210

211

212

213

A total of 200 cow heifers of unidentified genotype or low-producing XB primiparous cows were used as ET recipients. The selected animals were observed for natural estrus, and ET was performed on the 7th day after standing heat. The presence of a good quality CL (Bényei et al. 2006; Kayacik et al. 2006) was confirmed through rectal palpation/ultrasonography before ET. Embryos (15 from HF and 15 from XB) from each treatment group (Total = 90) were randomly allotted to the recipient cows through the lottery method. ET was performed non-surgically (Selk 2002), and pregnancy was checked by ultrasonography on the $45^{\text {th }}$ day after estrus to calculate the fertility results.

\subsection{Study Variables}

The data was collected through ultrasonography for the ovarian picture of donor cows. The ovulation and presence of CL were checked on the day of estrus (Day "0"), Day "8" respectively. The number of multiple follicles (Super-Estrus Follicles, i.e., SEFs) was checked on the day of super estrus. SEFs depict the success of FSH to recruit multiple follicles. The total number of multiple CLs (MCL) presented on the superovulated ovaries of each donor cow was checked on the day of embryo collection. MCLs indicate the successful ovulation of SEFs. All structures after non-surgical flushing were regarded as Total Structures Recovered (TSR). TSR were further dived into fertilized structures (Transferable Embryos, i.e., "TEs" and Degenerated Embryos, i.e., DGs) and unfertilized ova, i.e., UFO (Racowsky et al. 2010). The days taken by the animals to return to estrus (RTE) were also observed. Ovulation percentages and fertilization percentages for every donor cow were calculated based on MCLs to SEFs ratio and FSR to TSR, respectively. The recipient cows showing a viable fetus on ultrasonography (38 days) after embryo transfer were considered pregnant. The pregnant recipients to total embryos transferred ratio was used to calculate the fertility percentage (Tadesse et al. 2016).

\subsection{Statistical Analysis}


214 All collected data was analyzed using SPSS 26.0. The normality of the data was checked using

215 the Shapiro-Wilk test. The effects of a given treatment on ovarian structures (i.e., SEFs and

216 MCLs), TSR, FSR, TEs, DGs, UFO, days taken for RTE after embryo collection, ovulation

217 percentage, and fertilization percentage were analyzed by Kruskal-Wallis test (non-parametric).

218 Missing values for dependent variables were treated as missing without considering any case

219 exclusion. Embryo fertility data was analyzed by the Chi-square method. Resultant graphs were

220 generated using GraphPad Prism 8.2. All variations with a 95\% confidence interval $(P<0.05)$

221 were treated as significant. Results have been presented as mean \pm standard error of the mean

222 (SEM).

223

224

225

3. RESULTS:

\subsection{Embryo Production}

226

The total structures recovered (TSR) per collection remained significantly higher $(P<0.05)$ in

227

CIDR-GnRH (11.50+2.24) and CIDR-EB (10.80+1.66) groups as compared to the control

228

$(04.72 \pm 0.73)$. Similarly, the number of transferable embryos per collection was significantly

229

higher $(P<0.05)$ in CIDR-GnRH $(6.33 \pm 1.49)$ and CIDR-EB $(6.86 \pm 1.17)$ groups as compared to

230 the control (2.40+0.60). The results have been summarized in Fig 2.

231

232

\subsection{Super-stimulation, Ovulation, and Fertilization}

233

The mean number of super estrus follicles (SEF), ovulation percentages of these follicles, and percentage of fertilized structures recovered (FSR) remained significantly higher $(P<0.05)$ for CIDR-GnRH and CIDR-EB groups as compared to the control (Table 1).

\subsection{Return to Estrus}

After embryo collection, the mean number of days taken for return to estrus (RTE) were found significantly lower $(P<0.05)$ for both treatment groups as compared to the the control group. The mean value of RTE days for the CIDR-GnRH, CIDR-EB, and control group was $14.55 \pm 2.14,14.07 \pm 1.74$, and $22.86 \pm 2.27$, respectively.

3.4 Breed Effects

As discussed above, the overall trend of super-stimulation, multiple ovulation, fertilization, embryo production, and RTE days remained the same when breed differences (i.e., $\mathrm{XB}$ and HF) were considered. However, XB cows showed comparatively better results for both 
245 treatment groups' super-stimulation and embryo production parameters $(P<0.05)$. However, days

246 taken for RTE remained significantly $(P<0.05)$ lower for HF cows. A graphical illustration of

247 these results has been shown in Fig 3.

\section{$248 \quad 3.5$ Embryo Fertility Results}

249 Overall fertility percentage of embryo transfer trial remained $56.67 \pm 5.25$. On statistical analysis, 250 the fertility of TEs was neither affected significantly $(P>0.05)$ by the superovulation protocol 251 used nor by breed differences among the donor cows (Table 2).

252

\section{DISCUSSION}

In the dairy industry, increased TEs production per donor per collection is the most acknowledged criterion for measuring the effectiveness of any bovine superovulation protocol. This study revealed that TEs production by HF and XB donor cows was significantly increased with modified superovulation protocols under a subtropical environment. The limited application of bovine embryo transfer technology in the developing countries of the subtropical environment is attributed to a lack of technological know-how and the inadequate super-stimulatory response of native breeds (Sheetal et al. 2018). The development of non-surgical ET techniques has provided an opportunity to propagate the genetic potential of superior females. Integration of MOET in superior bovine females can help in the genetic improvement of existing dairy herds (Khan 2002). Due to the low milk production of domestic livestock breeds, Pakistan s introduced HF and Jersey Cattle to improve productivity (Lateef et al. 2008). However, these breeds can only be reared at controlled sheds due to heat stress-related problems and increased management costs. As a result, adversely impacting the overall dairy production economics (Tahir et al. 2019). as they have greater environmental variability adaptation and demonstrate a higher production performance (Hassan \& Khan 2013; Leroy et al. 2016)). Furthermore, the economically viable application of MOET protocols in elite XB cows can accelerate genetic gain and improve livestock production. (Granleese et al. 2015). Using the methodology described in section 2 and applied in the subtropical Pakistani environments with extreme climatic variations revealed an increased number of transferable embryos per donor per collection in HF and XB cows. 
275 Moreover, the results of this study highlighted the efficiency of three super-stimulatory

276 treatments subjected to $\mathrm{HF}$ and XB cows.

277 Increased understanding of the bovine estrous cycle's follicular wave dynamics has

278 stimulated the dairy industry's interests for precise control of follicle/corpus luteal dynamics and

279 ovulation timing (Abdelnaby et al. 2020). Follicular wave formation can be controlled

280 mechanically or synchronized by hormonal therapy. A follicular ablation by an ultrasound-

281 guided needle is performed for mechanical control, while for hormonal synchrony, GnRH or

282 estradiol combined with progesterone is recommended (Mikkola et al. 2020). It is worth noting

283 that CIDR's application supplemented with GnRH or EB prior to the initiation of super-

284 stimulatory treatment results in new follicular wave emergence and yields a higher number of

285 TEs than conventional super-ovulatory protocols (Jahnke \& Youngs 2021). The results of this

286 intensive study have demonstrated a great prospect of induced follicular wave emergence

287 treatments combined with super-ovulatory conventions. A similar superovulation study in Nelore

288 (beef cows) conducted in Brazil has produced comparable results (Andrade et al. 2003).

289 Traditionally, $80 \%$ of the cows exhibit the emergence of two follicular waves in such

290 type of experiments, whereas less than 20\% showed three follicular waves (Noseir 2003).

291 Therefore, superovulation protocols are designed according to the day of the 2nd follicle wave

292 emergence (9-12 $2^{\text {th }}$ of the estrous cycle) (Mapletoft et al. 2002). Synchrony between the time of

293 follicular wave emergence and the commencement of bovine superovulation protocols results in

294 improved response, whereas asynchrony (even for a day) negatively affects the in vivo embryo

295 production (KARA \& BEKYÜREK 2021). In our study, the follicular wave's emergence was

296 electively controlled using CIDR-GnRH or CIDR-EB. Afterward, superovulation treatment was

297 initiated at the expected time of follicular wave emergence.

298 The main objective of any super-ovulatory program is to produce the maximum number

299 of TEs per donor per collection. In our study, super-stimulatory response (i.e., number of SEF at

300 the time of super estrus and multiple CLs present on the day of embryo flushing) and in-vivo

301 embryo production (TEs) improved with the CIDR-GnRH or CIDR-EB based superovulation

302 treatment as compared to the control. These results were closer to the global mean TE

303 production in dairy cows, i.e., 5 per collection (Bó \& Mapletoft 2014 ). However, the

304 degenerated embryo production remained significantly higher (4.61 \pm 1.26 and 3.26 \pm 0.63 and

$3051.16 \pm 0.29$, respectively) for treatment groups compared to the control group. This may be due to 
306 the higher serum P4 values during super-estrus due to the CIDR application in the presence of 307 previous cycle CL. Other researchers have reported similar phenomena (Wiley et al. 2019;

308

309

310

311

312

313

314

315

316

317

318

319

320

321

322

323

324

325

326

327

328

329

330

331

332

333

334

335

336 KARA \& BEKYÜREK 2021). Therefore, it is suggested to analyze these facts in correlation to serum P4 values. A similar study on Korean native cattle (Bos Taurus) has reported no difference in treatment and conventional group (Son et al. 2007). The range of TE among the different groups was 4-6 per donor per collection. Another study on Nelore (beef) cows has produced a higher mean number of TE with CIDR-GnRH treatment without considering the estrous cycle stage (Andrade et al. 2003). However, the TEs production in beef cows is generally higher as compared to dairy cows. Another study on Bos Taurus x Bos indicus (5/8 Holstein and 3/8 Zebu, and 5/8 Brown swiss $x 3 / 8$ zebu) multiparous cows has reported more than seven TEs per donor per collection (Chacón et al. 2020). Another study from Egypt about using CIDR and EB in superovulation protocol has reported 4.75 TEs per donor in HF from the best performing group (AE et al.). However, the superovulation hormone used in this study was eCG. The results of our study were comparable to TE production from the middle-aged XB cow super-stimulated with CIDR-GnRH based superovulation under tropical conditions (Naranjo-Chacón et al. 2019). However, the TE production in treatment groups of our study was better than TE production from older XB cows (Naranjo-Chacón et al. 2019).

In hypothetical correspondence with studies which state that $\mathrm{GnRH}$ or porcine $\mathrm{LH}(\mathrm{pLH})$ administration results in ablation of a dominant follicle followed by the emergence of a new follicular wave 48-72 hours later (Macmillan \& Thatcher 1991; Pursley et al. 1995; Martinez et al. 1999; Thatcher et al. 1993; ERDEM et al. 2020), superovulation treatment was initiated on day 11 of the estrous cycle in our study.

Both treatment groups exhibited a similar wave emergence pattern (10.80 \pm 0.20 days $)$ and (10.33 \pm 0.21 days), respectively. However, GnRH may fail to ablate large follicles, resulting in non-synchronization of follicle wave emergence (Martinez et al. 1999; Guanga et al. 2020). To address this phenomenon, estradiol-17 $\beta$ has been experimented on progestin-implanted cows. Such studies have reported a new follicular wave within 3 to 5 days (Honparkhe et al. 2014; Singh et al. 2015). Although estradiol-17 $\beta$ is a short-acting drug, its use on a commercial scale is impossible in many countries due to legal restrictions. Therefore, other commercially available estrogen esters (i.e., estradiol benzoate or estradiol valerate) have also been experimented with, resulting in synchronous emergence of a new follicular wave within 3-4 days (Bo et al. 2002). 
337 The two most important factors affecting the variability in superovulation results are the stage of

338 the estrous cycle (follicular status of ovaries) and antral follicular count in donor cows (Bó et al.

339 2019). Based on the findings of this study and perusal of the literature, it can be inferred that

340 treating donor cows (for synchronization of follicular wave emergence) before initiating FSH

341 administration remains beneficial in enhancing in vivo TEs production. Furthermore, the

342 additional cost for the use of CIDR and GnRH/EB was much lower than its impact to improve

343 the TEs production per donor per collection. Hence, the experimented timeline can benefit the

344 dairy farmers by reducing the uncertainty about the suitable day (of estrous cycle) to start FSH

345 treatment for producing better results.

346 Under field conditions, it may not be easy to perform ultrasound scanning and follow

347 every cow to determine the exact day of follicular wave development. Hence a fixed timeline for

348 superovulation and embryo production needs to be implemented.

349 The time interval between two consecutive embryo collections and the future utility of a

350 superovulated cow is affected by the number of days taken by the animal for return to estrus

351 (RTE) after embryo collection. Previously, it has been established that gap of two regular estrous

352 cycles as a breeding rest is necessary (Bó \& Mapletoft 2014). Nevertheless, animals are being

353 collected repeatedly with a reduced time interval (Hasler 2010). The cows in the present study

354 exhibited first heat $17.33 \pm 3.50$ days and $16.07 \pm 3.36$ days after embryo collection in CIDR-

$355 \mathrm{GnRH}$ and CIDR-EB groups. Days taken by these groups for RTE were significantly lower

$356(P<0.05)$ than the control group, which may be correlated to a significantly higher $(P<0.05)$

357 ovulation rate in donor cows belonging to the treatment group. During the study, it was a general

358 observation that cows with unruptured or un-ovulated follicles (on the day of embryo collection)

359 took more days for RTE. However, more significant variations in the animals' days to come into

360 first heat after collection need to be further explored. The donors are superovulated after every

36130 to 40 days interval by many practitioners (Hasler 2014). Reducing the days taken for RTE

362 after embryo collection may help to achieve more TEs per donor per unit time (Bó \& Mapletoft

363 2014).

364 The fertility of embryos based on ET trials was not affected by the variation in super-ovulatory

365 treatments given and the breed of the donor cows. Similar studies have reported no adverse

366 effects on embryo fertility results in dairy or beef cows. (Andrade et al. 2002; KARA \&

367 BEKYÜREK 2021). 


\section{CONCLUSION}

It can be divulged from the present study that the addition of CIDR-GnRH or CIDR-EB

371

372

373

374

375

376

377

378

379

380

381

382

383

384

385

386

387

388

389

390

391

392

393

394

395

396

397

398

399

400

401

402

\section{ACKNOWLEDGEMENTS}

The authors are very thankful to the technical and other staff working at the Centre of Excellence for Bovine Genetics, Okara, for their help 7in conducting this study.

\section{CONFLICT OF INTEREST STATEMENT}

The authors declare no competing financial interests.

\section{DATA AVAILABILITY STATEMENT}

The supporting data has been uploaded as supplementary files.

\section{REFERENCES}

Abdel-Khalek A-KE-S. 2010. STUDY ON FOLLICULAR DYNAMICS IN SUPEROVULATED CATTLE. Faculty of Agriculture, Mansoura University.

Adams GP, and Singh J. 2021. Ovarian follicular and luteal dynamics in cattle. Bovine reproduction:292-323.

AE A, El-Keraby F, and El-Din AS. USE OF PROGESTERONE IN SUPEROVULATION PROTOCOLS FOR EMBRYO PRODUCTION IN FRIESIAN COWS.

Abdelnaby EA, Abo El-Maaty AM, and El-Badry DA. 2020. Ovarian and uterine arteries blood flow waveform response in the first two cycles following superstimulation in cows. Reproduction in Domestic Animals 55:701-710.

Andrade J, Oliveira M, Lima P, Santos Filho A, and Pina V. 2002. Use of steroid hormone treatments prior to superovulation in Nelore donors. Animal reproduction science 69:9-14.

Andrade J, Oliveira M, Lima P, Guido S, Bartolomeu C, Tenório Filho F, Pina V, Iunes-Souza T, Paula N, and Freitas J. 2003. The use of steroid hormones in superovulation of Nelore donors at different stages of estrous cycle. Animal reproduction science 77:117-125.

Baruselli PS, de Souza AH, de Sá Filho MF, Marques MO, and de Sousa Sales JN1. 2018. Genetic market in cattle (Bull, AI, FTAI, MOET and IVP): financial payback based on reproductive efficiency in beef and dairy herds in Brazil. Animal Reproduction (AR) 15:247-255.

Baumans V. 2005. Science-based assessment of animal welfare: laboratory animals. Revue Scientifique Et Technique-Office International Des Epizooties 24:503. 
403

404

405

406

407

408

409

410

411

412

413

414

415

416

417

418

419

420

421

422

423

424

425

426

427

428

429

430

431

432

433

434

435

436

437

438

439

440

441

442

443

444

445

446

447

448

Bényei B, Komlósi I, Pécsi A, Pollott G, Marcos CH, de Oliveira Campos A, and Lemes MP. 2006. The effect of internal and external factors on bovine embryo transfer results in a tropical environment. Animal reproduction science 93:268-279.

Bo GA, Baruselli PS, Moreno D, Cutaia L, Caccia M, Tribulo R, Tribulo H, and Mapletoft RJ. 2002. The control of follicular wave development for self-appointed embryo transfer programs in cattle. Theriogenology 57:53-72.

Bó GA, Guerrero DC, Tríbulo A, Tríbulo H, Tríbulo R, Rogan D, and Mapletoft RJ. 2009. New approaches to superovulation in the cow. Reproduction, Fertility Development 22:106-112.

Bó GA, and Mapletoft RJ. 2014. Historical perspectives and recent research on superovulation in cattle. Theriogenology 81:38-48.

Bó GA, Cedeño A, and Mapletoft RJ. 2019. Strategies to increment in vivo and in vitro embryo production and transfer in cattle. Animal Reproduction 16:411-422.

Chacón FN, Palacios FM, Sedano RC, and Ahuja-Aguirre C. 2020. Embryo production after superovulation of bovine donors with a reduced number of FSH applications and an increased eCG dose. Theriogenology 141:168-172.

ERDEM H, Alkan H, KARAŞAHIN T, DURSUN Ş, SATILMIŞ F, and GÜLER M. 2020. Retrospective evaluation of factors affecting superovulatory response in embryo production in Simmental cattle. Turkish Journal of Veterinary and Animal Sciences 44:1250-1259.

Galukande E, Mulindwa H, Wurzinger M, Roschinsky R, Mwai AO, and Sölkner J. 2013. Crossbreeding cattle for milk production in the tropics: achievements, challenges and opportunities. Animal Genetic Resources/Ressources génétiques animales/Recursos genéticos animales 52:111-125. 10.1017/s2078633612000471

Granleese T, Clark SA, Swan AA, and van der Werf JH. 2015. Increased genetic gains in sheep, beef and dairy breeding programs from using female reproductive technologies combined with optimal contribution selection and genomic breeding values. Genetics Selection Evolution 47:70.

Guanga L, Escandón P, Carpio E, Quito S, and Sanango J. 2020. Control of the emergence of the follicular wave by the application of oestradiol benzoate, gnrh and follicular ablation in the late metaoestrous in heifers in the high tropics. Revista de Investigaciones Veterinarias del Perú (RIVEP) 31.

Guerrero DC, Tríbulo A, Tríbulo R, Tríbulo H, and Bó G. 2009. SUPEROVULATORY RESPONSE IN BEEF DONORS TREATED DURING THE FIRST FOLLICULAR WAVE OR FOUR DAYS AFTER PROGESTERONE AND ESTRADIOL ADMINISTRATION. Reproduction, Fertility Development 22:358-358.

Hasler JF. 2010. Bovine embryo transfer: are efficiencies improving? Proc Appl Repro Strat Beef Cattle Nashville, TN http://www beefusa org/cmdocs/beefusa/resources/cc2011-beyondbovineembryo-transfer-efficiencies-tn-2010 pdf.

Hasler JF. 2014. Forty years of embryo transfer in cattle: A review focusing on the journal Theriogenology, the growth of the industry in North America, and personal reminisces. Theriogenology 81:152-169.

Hassan F, and Khan M. 2013. Performance of crossbred dairy cattle at military dairy farms in Pakistan. Journal of Animal and Plant Sciences 23:705-714.

Hassan M, Arfat M, Arshad U, and Ahmad N. 2021. Ovarian dynamics, hormone profiles, and characterization of ovarian and uterine blood flow in cycling Sahiwal cows. South African Journal of Animal Science 51:194-204.

Peer) reviewing PDF | (2021:03:59336:2:0:NEW 3 Aug 2021) 
Honparkhe M, Gandotra V, Matharoo J, Ghuman S, Dadarwal D, and Singh J. 2014. Synchronization of follicular wave emergence following ultrasound-guided transvaginal follicle ablation or estradiol$17 \beta$ administration in water buffalo (Bubalus bubalis). Animal reproduction science 146:5-14.

Jahnke MM, and Youngs CR. 2021. Superovulation in Cattle. Bovine Reproduction:1032-1040. Jarvis LS. 2019. Multiple Ovulation and Embryo Transfer (MOET). The Potential Effect of Two New Biotechnologies on the World Dairy Industry: CRC Press, 41-77.

KARA U, and BEKYÜREK T. 2021. The Effects of Pre-Superovulation GnRH and Short-Term Progesterone Administrations on the Quantity and Quality of Bovine Embryos. Journal of Faculty of Veterinary Medicine, Erciyes University/Erciyes Üniversitesi Veteriner Fakültesi Dergisi 18.

Kayacik V, SALMANOĞLU MR, Polat B, and ÖZLÜER A. 2006. Evaluation of the corpus luteum size throughout the cycle by ultrasonography and progesterone assay in cows. Turkish Journal of Veterinary and Animal Sciences 29:1311-1316.

Khan M. 2002. Prospects of multiple ovulation and embryo transfer (MOET) in genetic improvement of buffaloes. PAKISTAN VETERINARY JOURNAL 22:35-39.

Lateef M, Gondal K, Younas M, Sarwar M, Mustafa M, and Bashir M. 2008. Milk production potential of purebred Holstein Friesian and Jersey cows in subtropical environment of Pakistan. Pakistan Veterinary Journal 28:9.

Lawanson A, and Oduntan O. 2020. Emerging trends in animal reproductive technology-A review.

Leroy G, Baumung R, Boettcher P, Scherf B, and Hoffmann I. 2016. Sustainability of crossbreeding in developing countries; definitely not like crossing a meadow. Animal 10:262-273.

Macmillan KL, and Thatcher WW. 1991. Effects of an agonist of gonadotropin-releasing hormone on ovarian follicles in cattle. Biol Reprod 45:883-889.

Madalena F. 2008. How sustainable are the breeding programs of the global main stream dairy breeds?-The Latin-American situation. Total health 138:62.

Mapletoft R. 2006. Bovine embryo transfer: IVIS.

Mapletoft R, and Bó G. 2018. Innovative strategies for superovulation in cattle. Animal Reproduction (AR) 10:174-179.

Mapletoft RJ, Steward KB, and Adams GP. 2002. Recent advances in the superovulation in cattle. Reproduction Nutrition Development 42:601-611.

Mapletoft R. 2018. History and perspectives on bovine embryo transfer. Animal Reproduction (AR) 10:168-173.

Martinez MF, Adams GP, Bergfelt DR, Kastelic JP, and Mapletoft RJ. 1999. Effect of LH or $\mathrm{GnRH}$ on the dominant follicle of the first follicular wave in beef heifers. Anim Reprod Sci 57:23-33.

Mebratu B, Fesseha H, and Goa E. 2020. Embryo Transfer in Cattle Production and Its Principle and Applications. Int J Phar Biomedi Rese 7:40-54.

Mekonnen MM, and Hoekstra AY. 2012. A global assessment of the water footprint of farm animal products. Ecosystems 15:401-415.

Mikkola M, Hasler JF, and Taponen J. 2020. Factors affecting embryo production in superovulated Bos taurus cattle. Reproduction, Fertility and Development 32:104-124.

Murphy B. 2018. Equine chorionic gonadotropin: an enigmatic but essential tool. Animal Reproduction (AR) 9:223-230. 
494

495

496

497

498

499

500

501

502

503

504

505

506

507

508

509

510

511

512

513

514

515

516

517

518

519

520

521

522

523

524

525

526

527

528

529

530

531

532

533

534

535

536

Naderi MM, Sarvari A, Milanifar A, Boroujeni SB, and Akhondi MM. 2012. Regulations and ethical considerations in animal experiments: international laws and islamic perspectives. Avicenna journal of medical biotechnology 4:114.

Naranjo-Chacón F, Montiel-Palacios F, Canseco-Sedano R, and Ahuja-Aguirre C. 2019. Embryo production in middle-aged and mature Bos taurus $\times$ Bos indicus cows induced to multiple ovulation in a tropical environment. Tropical animal health and production 51:2641-2644.

Nasser L, Sá Filho M, Reis E, Rezende C, Mapletoft R, Bó G, and Baruselli P. 2011. Exogenous progesterone enhances ova and embryo quality following superstimulation of the first follicular wave in Nelore (Bos indicus) donors. Theriogenology 76:320-327.

Noseir WM. 2003. Ovarian follicular activity and hormonal profile during estrous cycle in cows: the development of 2 versus 3 waves. Reproductive Biology Endocrinology 1:1-6.

Phillips PE, and Jahnke MM. 2016. Embryo transfer (techniques, donors, and recipients). Veterinary Clinics: Food Animal Practice 32:365-385.

Pursley J, Mee M, and Wiltbank M. 1995. Synchronization of ovulation in dairy cows using PGF $2 \alpha$ and GnRH. Theriogenology 44:915-923.

Racowsky C, Vernon M, Mayer J, Ball GD, Behr B, Pomeroy KO, Wininger D, Gibbons W, Conaghan J, and Stern JE. 2010. Standardization of grading embryo morphology. Springer.

Rivera FA, Mendonca LG, Lopes G, Santos JE, Perez RV, Amstalden M, Correa-Calderon A, and Chebel RC. 2011. Reduced progesterone concentration during growth of the first follicular wave affects embryo quality but has no effect on embryo survival post transfer in lactating dairy cows. Reproduction 141:333.

Roche JR, Friggens NC, Kay JK, Fisher MW, Stafford KJ, and Berry DP. 2009. Invited review: Body condition score and its association with dairy cow productivity, health, and welfare. Journal of dairy science 92:5769-5801.

Roelofs J, López-Gatius F, Hunter R, Van Eerdenburg F, and Hanzen C. 2010. When is a cow in estrus? Clinical and practical aspects. Theriogenology 74:327-344.

Selk G. 2002. Embryo transfer in cattle.

Sheetal S, Prasad S, and Gupta H. 2018. Effect of insulin or insulin-like growth factor-I administration at mid-luteal phase of the estrous cycle during superovulation on hormonal profile of Sahiwal cows. Veterinary world 11:1736.

Singh N, Dhaliwal G, Malik V, Dadarwal D, Honparkhe M, Singhal S, and Brar P. 2015. Comparison of follicular dynamics, superovulatory response, and embryo recovery between estradiol based and conventional superstimulation protocol in buffaloes (Bubalus bubalis). Veterinary world 8:983.

Son D-S, Choe C-Y, Cho S-R, Choi S-H, Kim H-J, and Kim I-H. 2007. The effect of reduced dose and number of treatments of FSH on superovulatory response in CIDR-treated Korean native cows. Journal of Reproduction and Development 53:1299-1303.

Stringfellow DA, and Givens MD. 2017. A procedural guide and general information for the use of embryo transfer techno7logy emphasizing sanitary procedures. Manual of the International Embryo Transfer Society, 4th Edition.

Tadesse M, Degefa T, Jemal J, Yohanis A, and Seyum T. 2016. Evaluation of response to superovulation, estrous synchronization and embryo transfer in local Zebu or crossbred dairy cattle. Ethiopian Journal of Agricultural Sciences 26:27-35.

Peer) reviewing PDF | (2021:03:59336:2:0:NEW 3 Aug 2021) 
537 Tahir MN, Riaz R, Bilal M, and Nouman HM. 2019. Current Standing and Future Challenges of

538

539

540

541

542

543

544

545

546

547

548

549

550

551

552
Dairying in Pakistan: A Status Update. Milk Production, Processing and Marketing: IntechOpen.

Viana JHM, Figueiredo ACS, Gonçalves RLR, and Siqueira LGB. 2018. A historical perspective of embryo-related technologies in South America. Embrapa Recursos Genéticos e Biotecnologia-Artigo em anais de congresso (ALICE): Animal Reproduction, v. 15, supl. 1, p. 963-970, 2018. Abstract 098.

Warriach H, McGill D, Bush R, Wynn P, and Chohan K. 2015. A review of recent developments in buffalo reproduction - a review. Asian-Australasian journal of animal sciences 28:451.

Wheeler MB, Monaco E, Bionaz M, and Tanaka T. 2010. The role of existing and emerging biotechnologies for livestock production: toward holism. Acta Scientiae Veterinariae 38:s463-s484.

Wiley C, Jahnke M, Redifer C, Gunn PJ, and Dohlman T. 2019. Effects of endogenous progesterone during ovarian follicle superstimulation on embryo quality and quantity in beef cows. Theriogenology 129:54-60. 


\section{Figure 1}

Schematic diagram of three superovulation protocols for dairy cows.

(1a): CIDR-GnRH protocol, (1b): CIDR-EB Protocol, (1c): Conventional or Standard protocol.

Day 0: heat (Natural estrus), US: ultrasonography, CL: Corpus luteum, FSH: follicle-

stimulating hormone, EB: Estradiol Benzoate, Al: Artificial insemination, Collection: non-

surgical embryo collection through flushing 

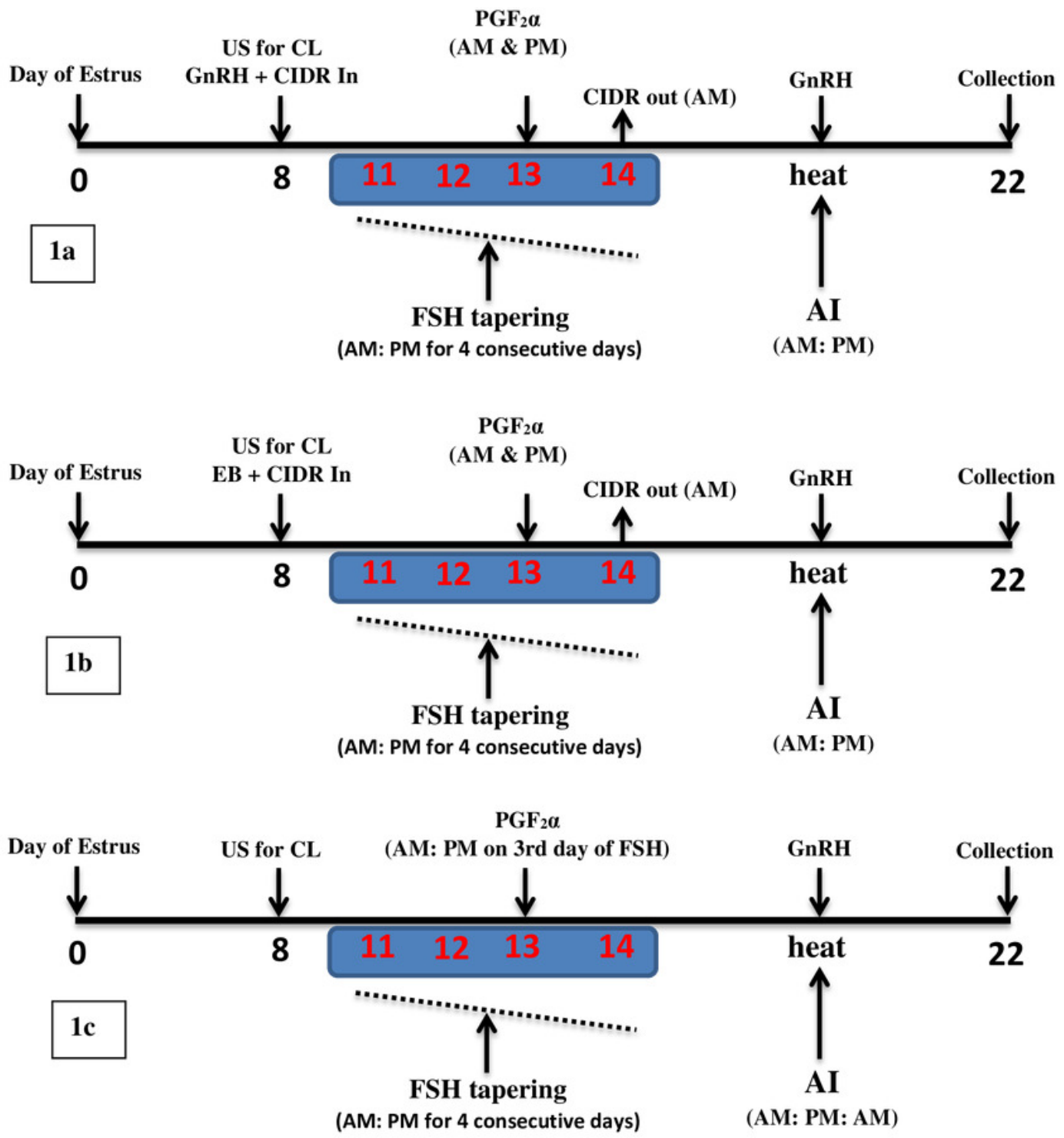
Figure 2

Mean ( + SEM) number of total structures recovered (TSR) and transferable embryos (TEs) in three different superovulation protocols.

${ }^{\text {ab }}$ Means without a common superscript differed $(\boldsymbol{P}<\mathbf{0 . 0 5})$ Ref to Fig. 1 for treatment protocols.

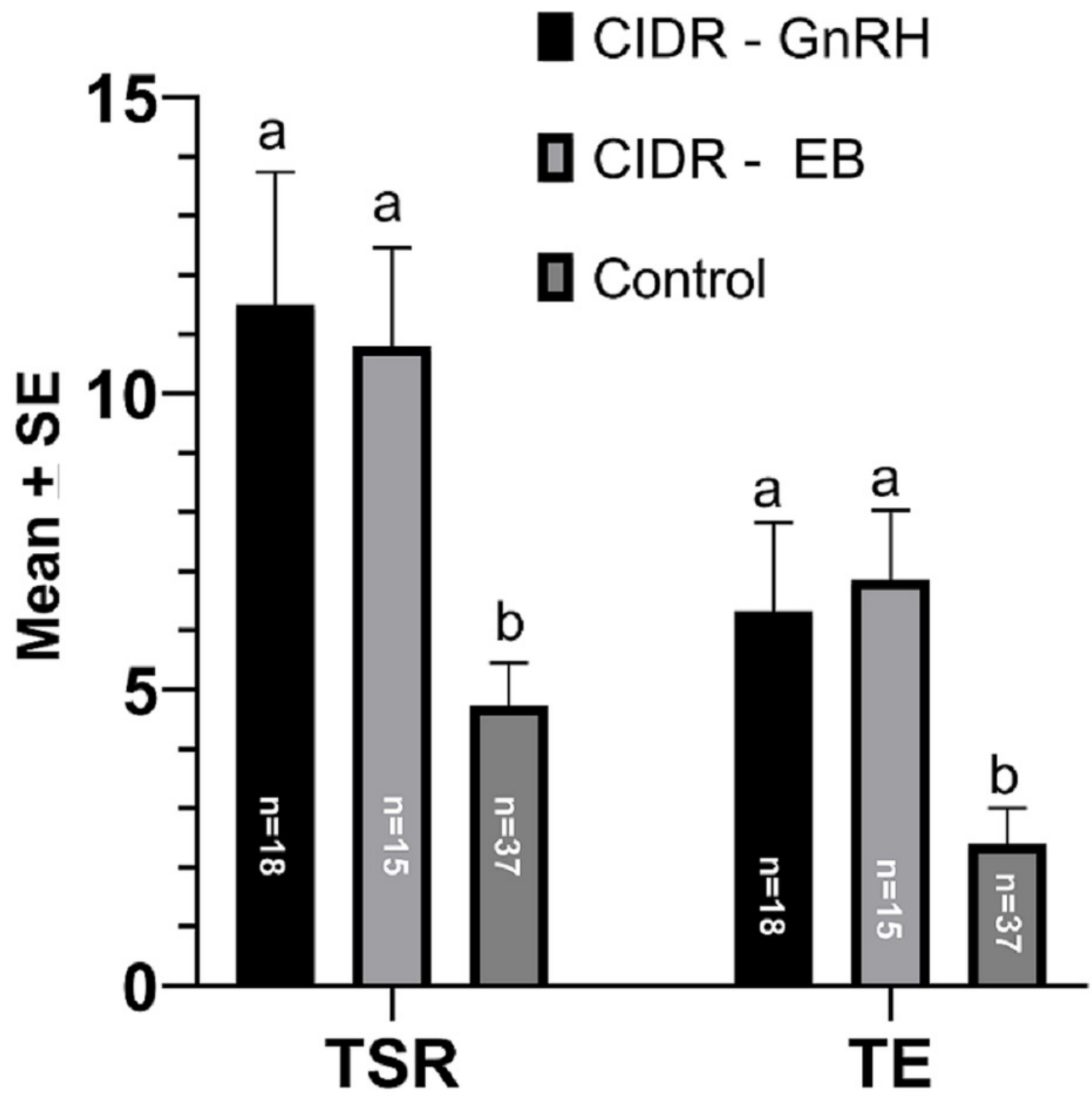


Figure 3

Comparative results of three different superovulation protocols in Crossbred (XB) and Friesian (Fri) cows

(a): Total structures recovered, (b): transferable embryos, (c): Multiple Corpora lutea,(d):

days to return to estrus. ${ }^{\text {acc }}$ Means without a common superscript differed $(\boldsymbol{P}<\boldsymbol{0 . 0 5})$. Ref to Fig. 1 for treatment protocols. 
(a)

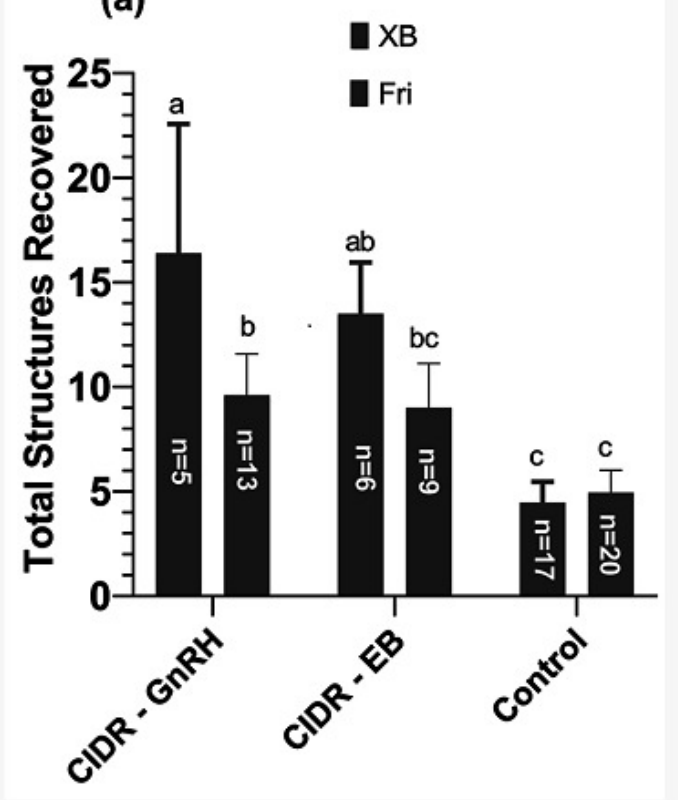

(c)

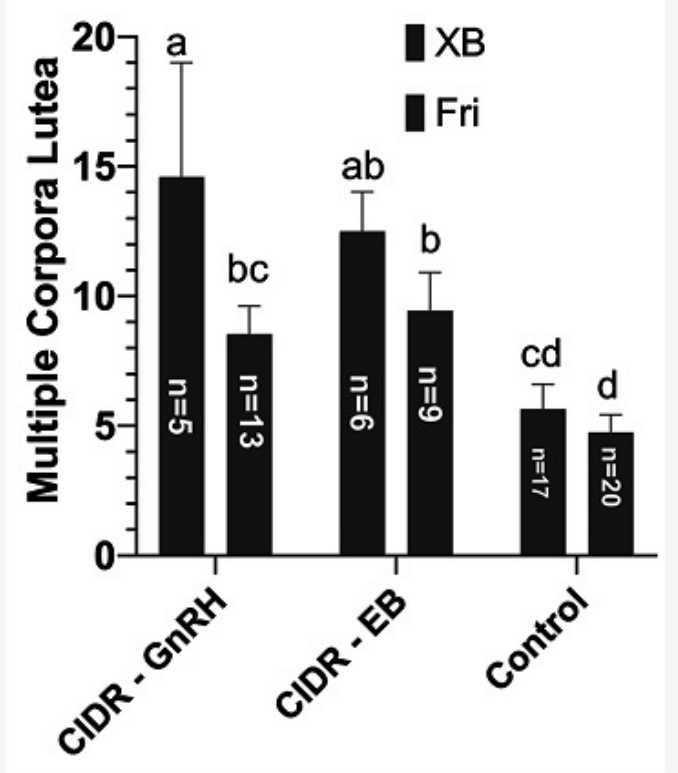

(b)

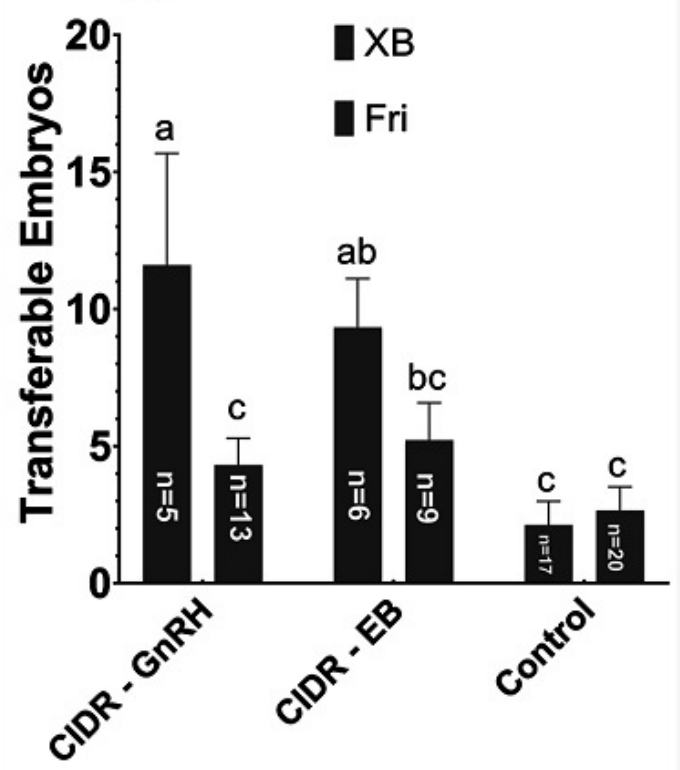

(d)

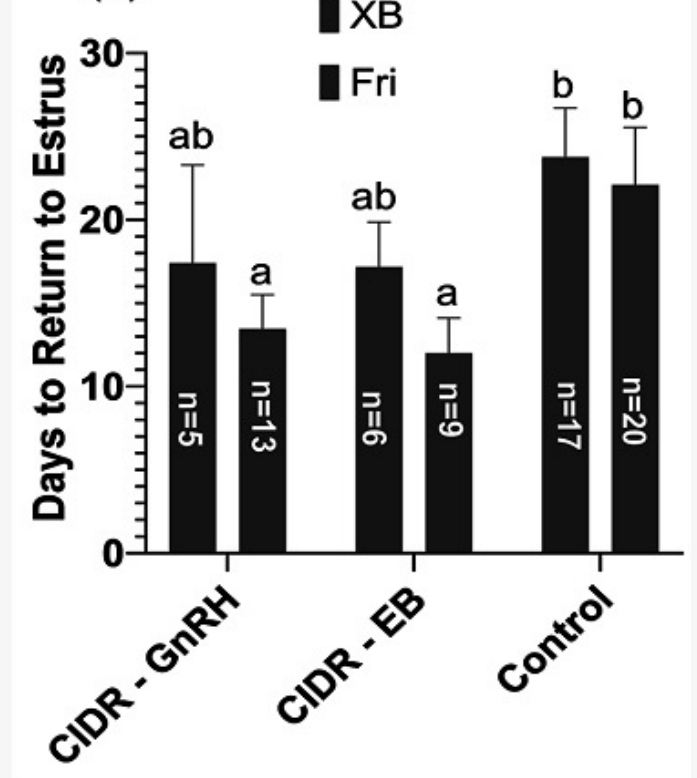




\section{Table $\mathbf{1}$ (on next page)}

Effect of CIDR-GnRH or CIDR-EB based Superovulation Protocols on Ovulation and Fertilization Percentage (Mean + SEM)

Ref to Fig. 1 for treatment protocol. Follicles (large follicles at super-estrus), Ovulation percentage (Percentage of super-estrus follicles which ovulated to form CLs on day of embryo collection), Fertilization percentage (Percentage of fertilized structures recovered (FSR), i.e. transferable and Degenerated embryos out of total structures recovered), UFO (Unfertilized ova), UFO percentage (Percentage of UFO out of TSR) ${ }^{\text {ab }}$ Within a column means without a common superscript differed $(P<0.05)$ 
1 Table. 1 Effect of CIDR-GnRH or CIDR-EB based Superovulation Protocols on Ovulation

2 and Fertilization Percentage (Mean \pm SEM)

\begin{tabular}{llccc}
\hline Protocol & $\begin{array}{l}\text { Follicles } \\
(\text { Number })\end{array}$ & $\begin{array}{l}\text { Ovulation } \\
\text { Percentage } \\
(\%)\end{array}$ & $\begin{array}{l}\text { Fertilization } \\
\text { Percentage } \\
(\%)\end{array}$ & $\begin{array}{c}\text { UFO } \\
\text { Percentage } \\
(\%)\end{array}$ \\
\hline CIDR - GnRH & $14.39 \pm 1.63^{\mathrm{a}}$ & $68.17 \pm 4.11^{\mathrm{a}}$ & $96.14 \pm 1.96^{\mathrm{a}}$ & $3.86 \pm 1.96^{\mathrm{a}}$ \\
$(\mathrm{n}=18)$ & & & & \\
CIDR - EB & $13.73 \pm 1.31^{\mathrm{a}}$ & $77.79 \pm 3.76^{\mathrm{a}}$ & $96.03 \pm 1.96^{\mathrm{a}}$ & $3.97 \pm 1.96^{\mathrm{a}}$ \\
$(\mathrm{n}=15)$ & & & & \\
Control & $08.00 \pm 0.63^{\mathrm{b}}$ & $58.50 \pm 4.84^{\mathrm{b}}$ & $57.60 \pm 6.62^{\mathrm{b}}$ & $28.88 \pm 5.75^{\mathrm{b}}$ \\
$(\mathrm{n}=37)$ & & & & \\
\hline
\end{tabular}

3

4 Ref to Fig. 1 for treatment protocol.

$5 \quad$ Follicles (large follicles at super-estrus), Ovulation percentage (Percentage of super-estrus

6 follicles which ovulated to form CLs on day of embryo collection), Fertilization percentage

7 (Percentage of fertilized structures recovered (FSR), i.e., transferable and Degenerated embryos

8 out of total structures recovered), UFO (Unfertilized ova), UFO percentage (Percentage of UFO

9 out of TSR)

10 ab Within a column means without a common superscript differed $(\boldsymbol{P}<\mathbf{0 . 0 5})$. 


\section{Table 2(on next page)}

Effects of Protocols / Breed Differences on Embryo Fertility (Mean + SEM)

Ref to Fig. 1 for treatment protocol. XB (Cholistani x HF crossbred cows), HF (Holstein Frisien Cows). ${ }^{\text {ab }}$ Within a column means without a common superscript differed $(\boldsymbol{P}<\mathbf{0 . 0 5})$. 
1 Table. 2 Effects of Protocols / Breed Differences on Embryo Fertility (Mean \pm SEM)

\begin{tabular}{|c|c|c|}
\hline Protocol & Breed & $\begin{array}{l}\text { Fertility } \\
\text { Percentage }\end{array}$ \\
\hline \multirow{2}{*}{ CIDR - C } & $\mathrm{XB}(\mathrm{n}=15)$ & $9 / 15(60.00 \%)^{\mathrm{a}}$ \\
\hline & $\mathrm{HF}(n=15)$ & $7 / 15(46.67 \%)^{a}$ \\
\hline \multirow{2}{*}{ CIDR - I } & $\mathrm{XB}(\mathrm{n}=15)$ & $9 / 15(60.00 \%)^{a}$ \\
\hline & $\mathrm{HF}(n=13)$ & $7 / 13(53.84 \%)^{a}$ \\
\hline \multirow{2}{*}{ Control } & $\mathrm{XB}(\mathrm{n}=15)$ & $10 / 15(66.67 \%)^{a}$ \\
\hline & $\mathrm{HF}(\mathrm{n}=17)$ & $9 / 17(52.94 \%)^{a}$ \\
\hline
\end{tabular}

2

3 Ref to Fig. 1 for treatment protocol. XB (Cholistani x HF crossbred cows), HF (Holstein Frisien 4 Cows $){ }^{a b}$ Within a column means without a common superscript differed $(\boldsymbol{P}<\boldsymbol{0 . 0 5})$. 5 